\title{
AN ASYMPTOMATIC RENAL MASS
}

\section{WALIUL ISLAM, SHARFORAZ ALI KHAN, ALIM AL RAZI, HABIBUR RAHMAN, SAFIUL ALAM}

Department of Urology, National Institute of Kidney Diseases \& Urology, Sher-Bangla Nagar, Dhaka

\begin{abstract}
Advancement in imaging techniques has now made it possible for small renal tumors to be detected incidentally. This has led to the use of minimally invasive techniques for treatment of these cases. A 40 year-old woman was diagnosed to have a small renal mass after routine abdominal ultrasonography for epigastric discomfort. Computed tomography scan was used to characterize the mass, and an elective partial nephrectomy was successfully carried out. The procedure is safe, less morbid, and has good oncological outcome.
\end{abstract}

Key words: Partial nephrectomy, nephron-sparing surgery, renal cell carcinoma

Bangladesh J. Urol. 2016; 19(1): 49-52

\section{Introduction}

Kidney tumors are the third most common genitourinary malignancy in adults, after prostate and bladder tumors $[1,2]$. They constitute about $3 \%$ of all human malignant tumors [3]. Renal cell carcinoma (RCC) is the most common primary malignant neoplasm of the kidney constituting about $85-90 \%$ of all renal tumors [4]. Before the advent of modern imaging techniques, most patients diagnosed with RCC presented with tumor-related symptoms [5]. In recent series from developed countries, $60-70 \%$ of patients with RCC are diagnosed asymptomatically and their tumors detected incidentally [6]. This has been attributed to the routine use of abdominal cross-sectional imaging to evaluate unrelated abdominal symptoms. In turn, this has led to the increasing use of minimally invasive techniques, for example, open partial nephrectomy, laparoscopic partial nephrectomy, robotic surgery, radiofrequency ablationand cryotherapy.

This case report is aimed at highlighting the asymptomatic presentation and incidental detection of RCC and the success of elective partial nephrectomy in the treatment of localized RCC in this environment.

Correspondence: Md. Waliul Islam Maruf, Department of Urology, National Institute of Kidney Diseases \& Urology, Sher-e-Bangla Nagar, Dhaka-1207, Email: uromaruf@gmail.com

\section{Case Report}

A 40 year-old married, school teacher was referred to National institute of kidney diseases \& urology with a 2year history of epigastric discomfort and headache and occasional right loin pain. Abdominal ultrasonography revealed a mass in the right kidney prompting a referral to kidney institute. Medical history revealed that she had been on treatment for peptic ulcer disease for 2 years and hypertension for 6 months before presentation with occasional relief of the epigastric discomfort. She was non-smoker and non-alcoholic. There was no family history of renal tumors.

A review of the abdominal ultrasound revealed a normal left kidney. The right kidney was normal in size with a mixed echogenic mass at its middle and lower pole. [figure: 1] The mass measured $5.2 \mathrm{~cm} \times 3.6 \mathrm{~cm}$.Computed tomography (CT) scan was requested to characterize the mass. This showed a exophytic cystic SOL having thick internal septation measuring about $5.8 \mathrm{~cm} \times 4.5 \mathrm{~cm}$ in mid and lower pole of right kidney(Bosniak type III).No wall calcification was seen. After I.V contrast, moderate enhancement are seen in margin and internal septation. The mass had a precontrast density of $4 \mathrm{HU}$ and a postcontrast density of $14 \mathrm{HU}$, suggesting some degree of vascularity [Figures 2 and 3]. Both kidneys showed prompt excretion of contrast and no calyceal dilatation. On FNAC, no malignant cell was seen. The patient was counseled for renal exploration with a possible partial nephrectomy with frozen section facilities. 


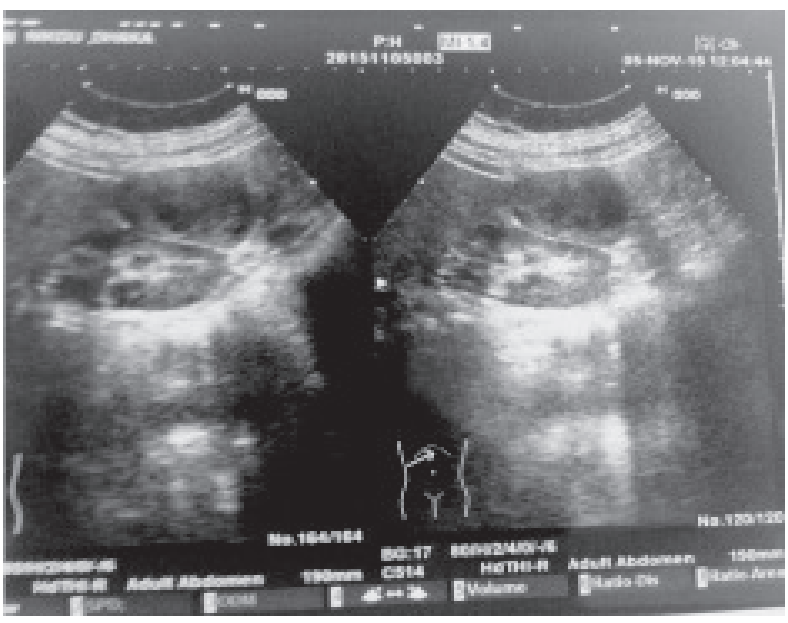

Fig.-1:

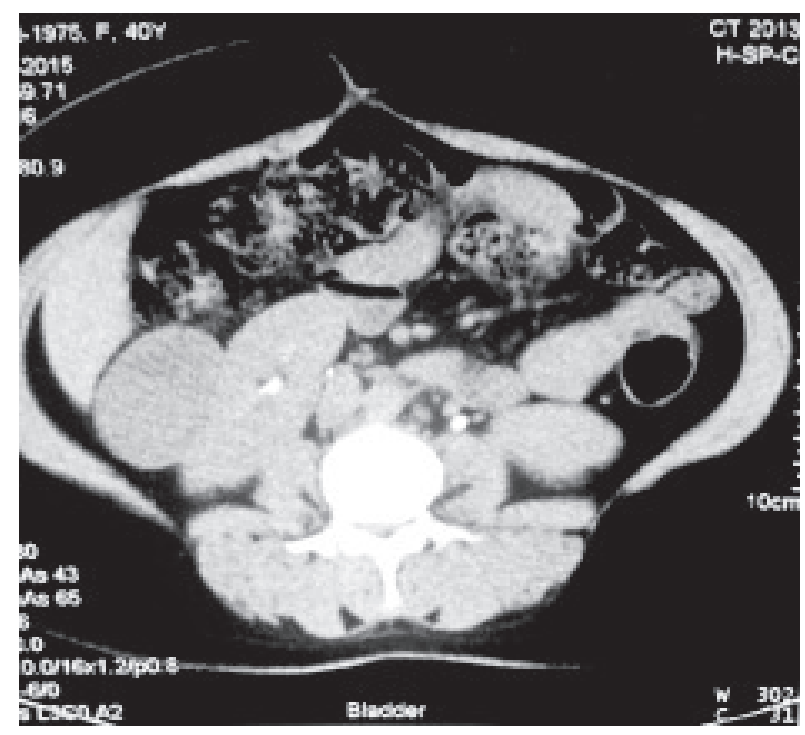

Fig.-2:

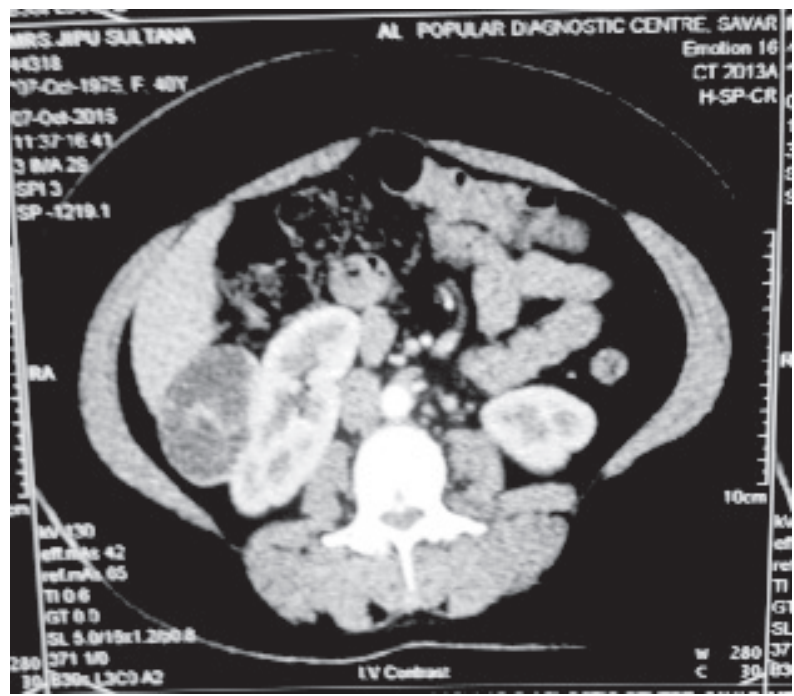

Fig.-3:

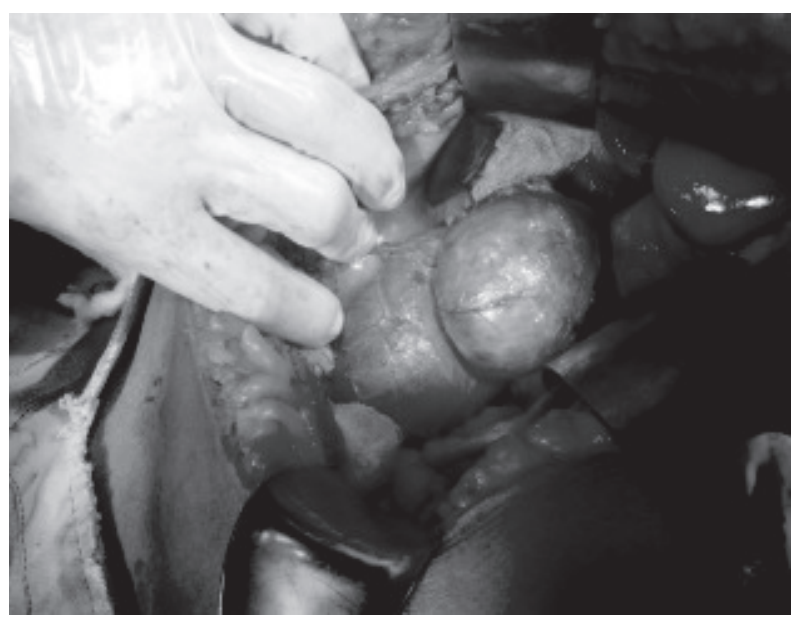

Fig.-4:

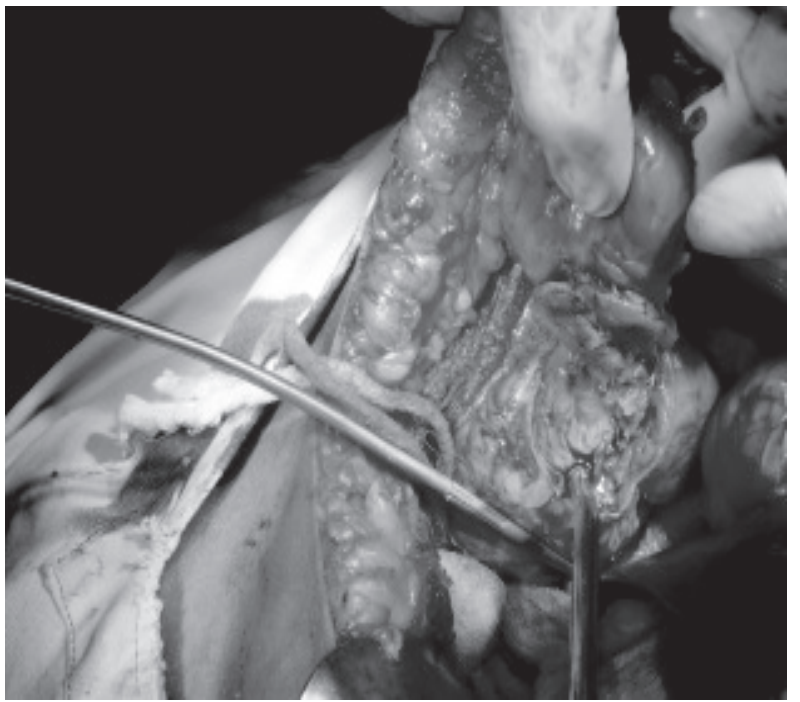

Fig.-5:

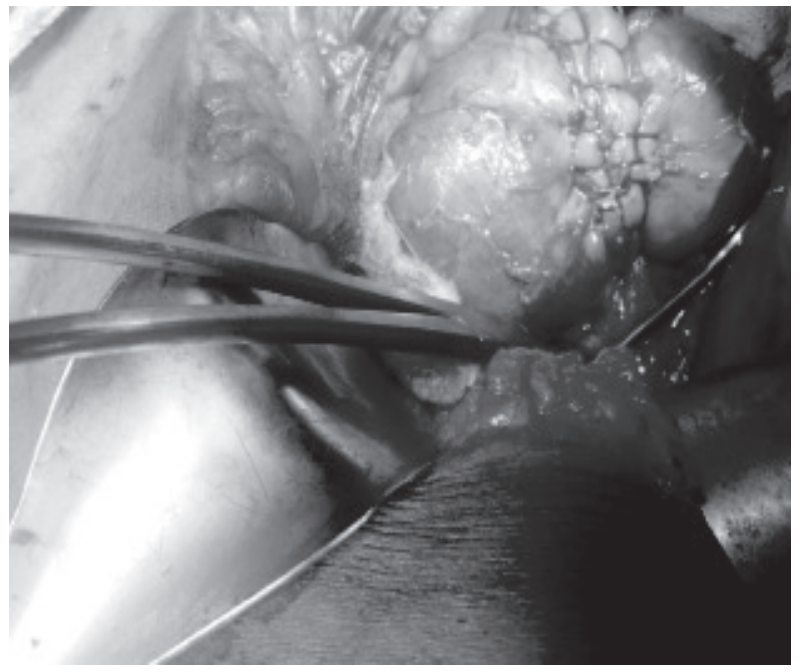

Fig.-6: 
Renal exploration was performed via a right subcostal flank incision, and the intraoperative finding was a well encapsulated exophytic mass in the mid and lower pole.[Figures 4-5]. Excision of renal mass with $1 \mathrm{~cm}$ margin was carried out after an initial occlusion of the renal artery and a cold ischemia obtained using ice slush application over the kidney for $15 \mathrm{~min}$. The collecting systems were noted to be intact without tumor infiltration. Few calices are opened and intra renal reconstruction was done after frozen section biopsy reports that was positive for malignant cell and cut margin free of tumour. Hemostasis was secured and the defect was closed with interrupted absorbable sutures vicryl. Recovery after surgery was uneventful. She was discharged on the seventh day. Histology of the excised mass revealed a chromophobe RCC with area of haemorrhage. She has been followed up at 3 and 6 months. Follow-up abdominal ultrasonography revealed a small sized right kidney with no evidence of tumor recurrence. Bio-chemical and liver function tests are normal. She will be followed up with regular ultrasonography and CT scanning.

\section{Discussion}

The incidence of kidney tumors has been noted to increase in the United States by $2.3-4.3 \%$ each year during the last three decades [7]. This increase may be due in part to improved diagnostic tests and better imaging techniques (CT scan, magnetic imaging resonance, ultrasonography). Thus, RCC may be referred to as a "radiologist tumor." The classic triad of loin pain, abdominal mass, and hematuria (too late triad) still remains the predominant mode of presentation of renal tumors in this environment[8]. This is a major setback in the effective management of patients with RCC. With increasing availability of newer imaging techniques such as CT scan and magnetic imaging resonance, the diagnosis and treatment of asymptomatic RCC is expected to increase in the future in our environment. This early detection will certainly improve survival of our patients who present late with grave complications.

Improved surgical techniques and methods of preventing ischemic renal injury and long-term cancer-free survival data have stimulated the expanded use of nephronsparing surgery for localized RCC tumors $(<4 \mathrm{~cm})$. Studies have shown open partial nephrectomy to be safe, with low morbidity and high patient satisfaction, and provides outstanding oncological and renal functional outcomes than radical nephrectomy $[9,10]$. Our index case fell into this category and was offered partial nephrectomy. Follow-up has also confirmed the effectiveness of this method of treatment in our index patient. Indications for partial nephrectomy can be absolute or relative. Elective partial nephrectomy is defined as treatment of a single small $(<4 \mathrm{~cm})$, clinically localized RCC in a patient with a normal contralateral kidney[11]. Chromophobe RCC comprises $5-10 \%$ of all RCCs and has a better prognosis than other subtypes[12].

Oncological outcomes for the subset of patients undergoing elective open partial nephrectomy are particularly outstanding. Cancer-specific survival rates of $94.5-97 \%$ at 10 years have been reported and recurrence only common in patients with systemic symptoms, larger tumors, and advanced pathological stage tumors[10,14] .

\section{Conclusions}

Incidentally detected asymptomatic renal masses should be properly assessed using the increasingly available high technology imaging techniques to better characterize their nature. This will lead to early detection and treatment with safer, less morbid surgical modalities such as partial nephrectomy. Elective open partial nephrectomy should be considered in all incidentally detected small, clinically asymptomatic renal masses. This procedure has been shown to have good oncological outcome in the long term $[9,10]$.

\section{Conflict of Interest : None declared}

\section{References}

1. Jemal A, Murray T, Ward E, Samauls A, Tiwari RC, Ghafoor A, et al. Cancer Statistics, 2005. CA Cancer J Clin 2005;55:10-30.

2. Mandong BM, lya D, Obekpa PO, Orkar KS. Urological tumors in Jos University Teaching Hospital, Jos, Nigeria (A hospital based histopathology study).Nig J Surg Res 2000;2:10813.

3. Jemal A, Siegal R, Ward E, Murray T, Xu J, Smigel C, et al. Cancer Statistics, 2006. CA Cancer J Clin 2006;56:106-30.

4. Motzer RJ, Bander NH, Nanus DM. Renal cell carcinoma. N Eng J Med 1996;335:865-75.

5. rispen PL, Uzzo RG. The natural history of untreated renal masses. BJU Int 2007;99:1203-7.

6. Parsons JK, Schoenberg MS, Carter HB. Incidental renal tumors: casting doubts on the efficacy of early intervention. Urology 2001;57:1013-5. 
7. Chow WH, Devesa SS, Warren JL, Fraumeni JF Jr. Rising incidence of renal cell cancer in the United States. JAMA 1999;281:1628-31.

8. Badmus TA, Salako AA, Arogundade FA, Sanusi AA, Adesunkanmi AR, Oyebamiji EO, et al. Malignant renal tumors in adults: A ten-year review in a Nigerian hospital. Saudi J Kidney Dis Transpl 2008;19:120-6.

9. Herr HW. Partial nephrectomy for unilateral renal cell carcinoma and a normal contralateral kidney: 10 year followup. J Urol 1999;161:33-5.

10. Fergany AF, Hafez KS, Novick AC. Long term results of nephron sparing surgery for localized renal cell carcinoma: 10 years follow-up. J Urol 2000;163:442-5.

11. Lane BR, NovickAC. Nephron-sparing surgery. BJU Int 2007;99:1245-50
12. Cheville JC, Lohse CM, Zincke H, Weaver AL, Blute ML. Comparisons of outcome and prognostic features among histologic subtypes of renal cell carcinoma. Am J SurgPathol 2003;27:612-24.

13. Knight DA, Stadler WM. Prognostic factors in localised renal cell cancer. BJU Int 2007;99: 1212-6.

14. Pahernick S, Roos F, Hampel C, Gillitzer R, Melchior SW, Thuroff JW. Nephron sparing surgery for renal cell carcinoma with normal contralateral kidney: 25years of experience. J Urol 2006;175:2027-31.

\footnotetext{
Abbreviations:

RCC : Renal Cell Carcinoma

SOL : Space Occupying Lesion
} 